\title{
Transient Hepatic Elastography in the Assessment of Liver Fibrosis in Patients After Liver Transplantation
}

\author{
Larisse Longo ${ }^{1,2}$ (D) - Matheus Henrique Mariano Pereira ${ }^{1,3}$ (D) - Deivid Cruz dos Santos ${ }^{3}$ (D) - Matheus \\ Trucollo Michalczuk ${ }^{2,4}$ (D) . Carlos Thadeu Schmidt Cerskii ${ }^{2,3,5}$ (1) • Mário Reis Álvares-da-Silva ${ }^{1,2,3,4}$ (i) \\ ${ }^{1}$ Experimental Laboratory of Hepatology and Gastroenterology, Center for Experimental Research, Hospital de Clinicas de Porto Alegre. \\ ${ }^{2}$ Graduate Program in Gastroenterology and Hepatology, Universidade Federal do Rio Grande do Sul. Porto Alegre, Brazil. \\ ${ }^{3}$ School of Medicine, Universidade Federal do Rio Grande do Sul. \\ ${ }^{4}$ Division of Gastroenterology, Hospital de Clinicas de Porto Alegre. \\ ${ }^{5}$ Division of Surgical Pathology, Hospital de Clinicas de Porto Alegre. \\ Porto Alegre, Brazil.
}

Acta Gastroenterol Latinoam 2021;51(3):314-320

Received: 20/03/2021 / Accepted: 30/08/2021 / Published online: 27/09/2021 / https://doi.org/10.52787/wdom2933

\section{Summary}

Introduction and Objectives. Liver biopsy is the gold standard for assessing fibrosis and inflammation in liver transplant recipients. As this study has risks, the use of noninvasive tools has been proposed, including transient elastography, a method that needs further study in this population, which is the purpose of this research. Material and methods. Demographic and clinical data were collected retrospectively in patients who received a liver transplant, underwent liver biopsy and transient elastography less than 1 year apart. Sensitivity, specificity, diagnostic accuracy and Kappa concordance test between the two methods were determined. Results. Of 356 patients evaluated after transplantation, 45 underwent liver biopsy and transient elastography within 1 year; $60.0 \%$ were male and $75.6 \%$ had hepatitis C virus infection. At the time of transient elastography, laboratory values were:
Correspondence: Larisse Longo

Hospital de Clinicas de Porto Alegre, Brazil

Email: larisselongo@hotmail.com mean total bilirubin $1.5 \mathrm{mg} / \mathrm{dL}$, alanine aminotransferase $108.1 \mathrm{U} / \mathrm{L}$, aspartate aminotransferase, 101.6 U/L, alkaline phosphatase, $96.0 \mathrm{U} / \mathrm{L}$ and gamma-glutamyl transferase $9.0 \mathrm{U} / \mathrm{L}$. The main indications for liver biopsy were assessment for rejection, hepatitis $C$ virus infection or both. According to liver biopsy, $82.2 \%$ presented absent or minimal fibrosis and $75.6 \%$ had no inflammation. Acute cellular rejection was present in $20.0 \%$ of cases. A cut-off point of $>9.5 \mathrm{kPa}$ was used to define advanced fibrosis, while a value $<7.5 \mathrm{kPa}$ was set to indicate absent or mild fibrosis. Poor agreement was found between transient elastography and liver biopsy for these categories (Kappa 0.125, sensitivity $69.5 \%$, specificity 66.7\%) and for specific stages of fibrosis (Kappa 0.095). Conclusions. Accuracy, sensitivity and specificity were low for fibrosis staging when comparing transient elastography with liver biopsy. In liver transplant recipients, transient elastography could overestimate fibrosis, probably due to inflammation secondary to other causes.

Keywords. Liver biopsy, liver transplant, transient elastography.

\section{Elastografía hepática transitoria en la evaluación de la fibrosis hepática en pacientes después de un trasplante de hígado}

\section{Resumen}

Introducción y objetivos. La biopsia hepática es el estudio de referencia para evaluar la fibrosis y la inflamación en los 
receptores de un trasplante de higado. Al ser un estudio que conlleva riesgos, se ha propuesto utilizar herramientas no invasivas, entre ellas la elastografía transitoria, método que requiere mayor investigación en esta población, propósito de esta investigación. Material y métodos. Se recopilaron en forma retrospectiva datos demográficos y clínicos de pacientes que recibieron un trasplante de higado, se sometieron a una biopsia hepática y a una elastografia transitoria con menos de 1 año de diferencia. Se determinó la sensibilidad, especificidad, precisión diagnóstica y la prueba de concordancia Kappa entre los dos métodos. Resultados. De 356 pacientes evaluados luego del trasplante, 45 fueron sometidos a biopsiahepática y elastografía transitoria en el plazo de 1 año. El 60\% eran varones y el 75,6\% tenía infección por virus de la hepatitis C. Al momento de la elastografía transitoria, los valores de laboratorio fueron: bilirrubina total media $1,5 \mathrm{mg} / \mathrm{dL}$, alanina aminotransferasa 108,1 U/L, aspartato aminotransferasa 101,6 U/L, fosfatasa alcalina 96,0 U/L y gamma-glutamil transferasa 9,0 U/L. Las principales indicaciones para la biopsia hepática fueron la evaluación del rechazo, la infección por virus de la hepatitis $C$ o ambos. Según la biopsia hepática, el $82,2 \%$ presentaba fibrosis ausente o minima y el 75,6\% no presentaba inflamación. En el 20\% de los casos estuvo presente el rechazo celular agudo. Para definir fibrosis avanzada se utilizó un valor límite $>9,5 \mathrm{kPa}$, mientras que para indicar fibrosis ausente o leve se fijó un valor $<7,5 \mathrm{kPa}$. Se encontró baja concordancia entre la elastografia transitoria y la biopsia hepática para estas categorías (Kappa 0,125; sensibilidad 69,5\%; especificidad 66,7\%) y para etapas especificas de fibrosis (Kappa 0,095). Conclusiones. La precisión, sensibilidad y especificidad fueron bajas para la estadificación de la fibrosis al comparar la elastografía transitoria con la biopsia hepática. En los receptores de trasplante hepático la elastografia transitoria sobreestimaría la fibrosis, probablemente por inflamación secundaria a otras causas.

Palabras claves. Biopsia hepática, trasplante de hígado, elastografia transitoria
Abbreviations
ALT: Alanine aminotransferase.
AST: Aspartate aminotransferase.
BMI: Body mass index.
CI: Confidence interval.
HCC: Hepatocellular carcinoma.
$H C V$ : Hepatitis $C$ virus.
$I Q R$ : Interquartile range.
INR: International normalized ratio.
kPa: Kilopascals.
LT: Liver transplant.
NAFLD: Nonalcoholic fatty liver disease.

SPSS: Statistical Package for the Social Sciences.

TE: Transient elastography.

\section{Introduction}

The development of liver fibrosis and its progression to cirrhosis adversely affects the prognosis of any chronic liver disease and is one of the leading cause of mortality worldwide. ${ }^{1,2}$ In the specific scenario of liver transplantation (LT), recurrent liver fibrosis leads to reduced graft survival and the need for a new transplant, which affects overall survival. ${ }^{3,4}$ Therefore, early identification allows for risk stratification and prognosis providing a basis for interventions aimed at therapeutic management. ${ }^{1}$ Liver biopsy is considered the gold standard for the diagnosis and staging of liver fibrosis and despite being a safe procedure, it is invasive, expensive and may cause complications. ${ }^{2,5,6}$ These difficulties prompted the development of non-invasive, reproducible and highly accurate methods to assess the stage of liver fibrosis. ${ }^{5}$

Transient tissue elastography (TE) is a non-invasive method used to stage the degree of liver fibrosis in patients with acute and chronic liver disease. ${ }^{7,8}$ It is a safer alternative to liver biopsy and has been increasingly incorporated into clinical practice, having recently been shown to be useful both in patients with early-stage liver disease and, to some extent, in post-LT patients. ${ }^{79}$ Despite the advantages of being a non-invasive method with a short application time, there are several factors that can influence the results obtained, such as the elevation of aminotransferases, cholestasis, inflammatory processes and hepatic steatosis, as well as the presence of ascites, hepatic congestion and obesity, among others. ${ }^{7,10}$ These factors may produce falsely elevated results and prevent their correct interpretation, leading to inconclusive results. ${ }^{7,} 10$ Immunosuppressive therapies can cause false negative results in the evaluation by TE, which may be related to the interference of necroinflammatory activity and overlap between the stages of liver fibrosis.

Therefore, there is a debate about the true role of TE in post-LT patients, since both inflammation and factors associated with the metabolic syndrome (frequently observed in this population) may influence the results. ${ }^{11-13}$ Focusing on these issues, the aim of this study is to evaluate the performance of TE, compared with the METAVIR scoring system obtained by performing a liver biopsy, for the diagnosis of liver fibrosis in post-LT patients at a university hospital in southern Brazil.

\section{Patients and Methods}

A retrospective cross-sectional study was performed, analyzing data from the medical records of patients who 
underwent LT at a referral service of a university hospital in southern Brazil between 2002 and 2016. PostLT patients who underwent liver biopsy and TE with an interval less than 365 days were included, regardless of underlying etiology. Percutaneous liver biopsy was performed accordingly clinical indication, for suspected rejection, acute hepatitis or disease recurrence. Patients underwent local anesthesia and the biopsy was performed with a cutting needle $(16 \mathrm{G})$. Fragments with more than $15 \mathrm{~mm}$ and 10 portal triads were considered suitable for anatomopathological analysis. Fibrosis was assessed according to the METAVIR classification. Elastography was performed as indicated by the attending physician. The Fibroscan 502 (Echosens, Paris, France) device was used. Only results with 10 valid measurements and IQR/ med less than 30,0\% were considered.

Clinical, laboratory, and demographic data were collected from the medical records of these patients. Clinical and laboratory data were obtained from the registries closest to the date the TE was performed, since the aim was to evaluate the efficacy of TE. Body mass index (BMI) was calculated and classified as healthy weight $\left(18.5 \mathrm{~kg} / \mathrm{m}^{2}-24.9 \mathrm{~kg} / \mathrm{m}^{2}\right)$, overweight $\left(25 \mathrm{~km} / \mathrm{m}^{2}\right.$ $\left.29.9 \mathrm{~kg} / \mathrm{m}^{2}\right)$ or obesity I $\left(30 \mathrm{~kg} / \mathrm{m}^{2}-34.9 \mathrm{~kg} / \mathrm{m}^{2}\right)$ for adults (18 - 59 years), and normal weight $\left(22 \mathrm{~kg} / \mathrm{m}^{2}\right.$ $26.9 \mathrm{~kg} / \mathrm{m}^{2}$ ) or overweight (over $27 \mathrm{~kg} / \mathrm{m}^{2}$ ) for elderly participants over the age of 60 years. ${ }^{14}$

This study was approved by the Ethics Committee of the Hospital de Clínicas de Porto Alegre (CAAE: 64393116.8.0000.5327) and conducted in accordance with guidelines for human studies.

\section{Statistical Analysis}

Quantitative variables were expressed as mean \pm standard deviation or median and interquartile range (25th75 th). Categorical variables were expressed as frequencies and percentages. Data were stored and processed with the Statistical Package for the Social Sciences, version 18.0 (SPSS Inc, Chicago, IL, USA). This program was used to compare groups of continuous variables using the Kruskal-Wallis test. To evaluate the degree of concordance between the results obtained for fibrosis stage according to liver biopsy and TE, McNemar's test and the Kappa coefficient were used, with $\mathrm{R}$ Caret, version 6.0-85 (caret package). Results with $p \leq 0.05$ were considered statistically significant.

\section{Results}

\section{General Characteristics of Patients}

From 2002 to 2016, 356 LTs were performed in a referral service. Of these, 64 (18.0\%) patients underwent at least one liver biopsy and TE after receiving LT, regardless of etiology. However, 19 (29.7\%) of these cases were excluded because the time elapsed between liver biopsy and TE exceeded 365 days, there was no description of the fibrosis stage or TE results were inconclusive. Therefore, a total of $45(70.3 \%)$ patients were included in this study. The study participant selection flowchart is shown in Figure 1.

Figure 1. Algorithm for the selection of patients undergoing liver transplantation and subsequently liver biopsy and ET

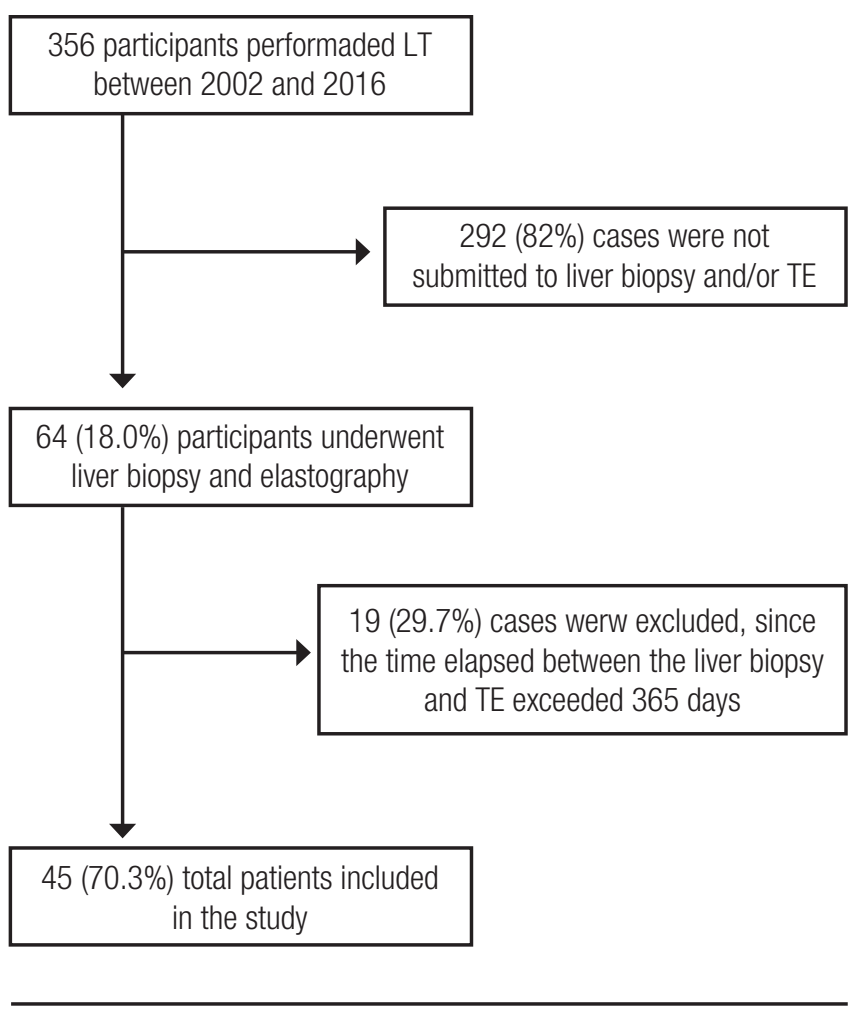

LT: liver transplant; TE: transient elastography.

Among the participants included in this study, the median time between LT and liver biopsy was 2.1 (0.9 - 4.8) years and between the LT and the TE was 2.4 (1.0 - 12.0) years. Additionally, the median time between the liver biopsy after TE was 169 (19.5 - 303.5) days. Table 1 shows demographic, laboratory and clinical data of the patients. The mean age at which LT was performed was $58.0(50.1-65.9)$ years and male sex was more frequent $(60.0 \%)$. The most frequent underlying etiology responsible for causing LT was hepatitis $\mathrm{C}$ virus infection (HCV - 75.6\%), followed by HCV along with alcohol abuse (20.0\%). The mean BMI was $26.2 \mathrm{~kg} / \mathrm{m}^{2}$ and overweight was the most frequent category $(51.1 \%)$ 
Table 1. Baseline Patient Characteristics at the Time of Transient Elastography

\begin{tabular}{|c|c|}
\hline Variables* & Patients $(n=45)$ \\
\hline Age at Liver Transplant & $58.0(50.1-65.9)$ \\
\hline \multicolumn{2}{|l|}{ Sex } \\
\hline Male & $27(60.0)$ \\
\hline Body Mass Index & $26.2( \pm 4.4)$ \\
\hline Healthy weight & $15(33.4)$ \\
\hline Overweight & $23(51.1)$ \\
\hline Obesity I & $6(13.3)$ \\
\hline Not available & $1(2.2)$ \\
\hline \multicolumn{2}{|l|}{ Etiology } \\
\hline $\mathrm{HCV}$ & $34(75.6)$ \\
\hline HCV + Alcohol abuse & $9(20.0)$ \\
\hline Alcohol abuse & $1(2.2)$ \\
\hline NAFLD & $1(2.2)$ \\
\hline \multicolumn{2}{|l|}{ Laboratory Parameters } \\
\hline ALT (U/L) & $108.1( \pm 113.0)$ \\
\hline AST (U/L) & $101.6( \pm 133.1)$ \\
\hline Bilirubin (mg/dL) & $1.5( \pm 3.0)$ \\
\hline Indirect bilirubin (mg/dL) & $0.6( \pm 0.8)$ \\
\hline Albumin (g/dL) & $4.3(4.1-4.6)$ \\
\hline Sodium (mEq/L) & $141.0(139.0-142.0)$ \\
\hline Creatinine (mg/dL) & $0.94(0.80-1.05)$ \\
\hline INR & $1.0(0.96-1.06)$ \\
\hline \multicolumn{2}{|l|}{ Ascites } \\
\hline Absent & $40(88.9)$ \\
\hline Mild & $3(6.7)$ \\
\hline Moderate & $2(4.4)$ \\
\hline \multicolumn{2}{|l|}{ Encephalopathy } \\
\hline Absent & 43 (95.5) \\
\hline Mild & $2(4.4)$ \\
\hline
\end{tabular}

*Variables expressed as frequency (\%), mean \pm standard deviation or median $\left(25^{\text {th }}-75^{\text {th }}\right.$ percentiles). Abbreviations: (ALT) alanine aminotransferase, (AST) aspartate aminotransferase, (HCV) hepatitis C virus, (INR) international normalized ratio and (NAFLD) nonalcoholic fatty liver disease.

among the cases evaluated. The majority of the patients studied had no diagnosis of ascites $(88.9 \%)$ or hepatic encephalopathy $(95.5 \%)$ at the time of liver biopsy and TE.

\section{Relationship between Histological Findings and Liver Stiffness}

Liver biopsy was indicated as an annual procedure as part of the institutional protocol in $15(33.3 \%)$ cases. In another $15(33.3 \%)$ cases it was indicated to assess acute cellular rejection, in $8(17.8 \%)$ patients the indication was to evaluate fibrosis staging and in 7 (15.6\%) cases to assess viral recurrence. The METAVIR classification score was used to grade liver biopsy results, showing that $37(82.2 \%)$ cases evaluated after LT had not fibrosis (F0) or minimal fibrosis (F1). Of the remaining cases, 5 (11.1\%) had moderate fibrosis (F2) and $3(6.7 \%)$ had advanced fibrosis or cirrhosis (F3/F4). Regarding necroinflammatory activity, used to estimate the degree of portal lesions and hepatocellular necrosis, an absence of acute inflammation was observed in $34(75.6 \%)$ cases, while the remaining cases did have inflammatory activity (11 cases - 24.4\%). Recurrence of hepatitis C after LT was found in $26(57.8 \%)$ liver biopsy reports and acute cellular rejection was reported in $9(20.0 \%)$ cases.

Figure 2 illustrates the distribution of stiffness values determined by TE, grouped by METAVIR scores. Liver stiffness values ranged from 1.7 to $57.1 \mathrm{kPa}$, with an overall median of $6.8 \mathrm{kPa}$ (IQR: 11.3 - 20.0). Broken down by METAVIR scores, the median stiffness value for the 23 cases classified as F0/F1 was $5.3 \mathrm{kPa}$ (IQR: 11.0 - 19.3), the median stiffness was $8.1 \mathrm{kPa}$ (IQR: 11.5 - 18.7) for the $7 \mathrm{~F} 2$ cases, and the 15 cases classified as F3/F4 had median stiffness of $17.2 \mathrm{kPa}$ (IQR: 12.0 - 21.0). The median stiffness values, obtained from the analysis by $\mathrm{TE}$, were significantly lower among patients

Figure 2. Distribution of liver stiffness values assessed by elastography, stratified by METAVIR scores

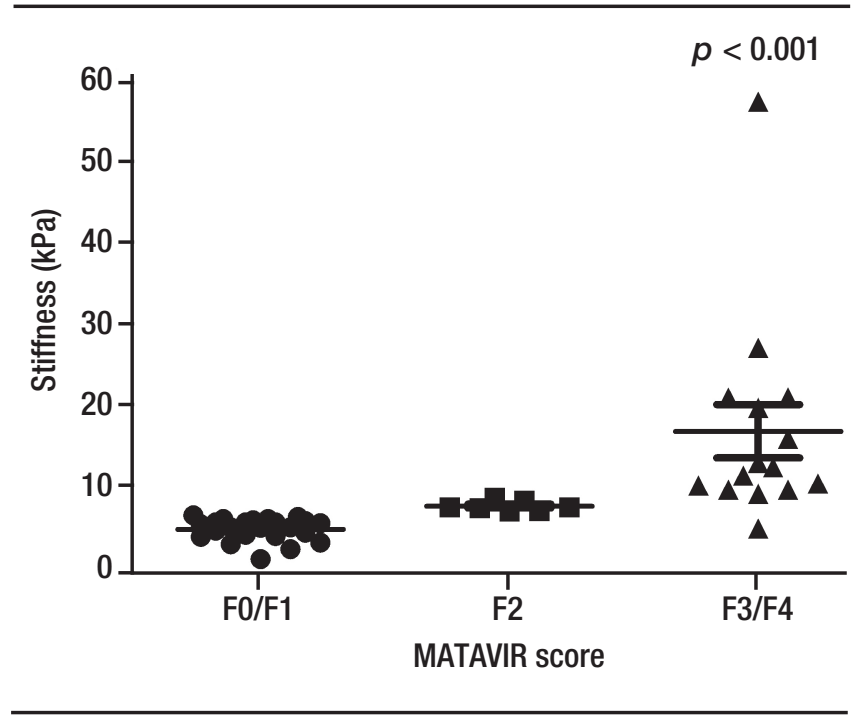

The top and bottom of the boxes are the 1st and 3rd quartiles.

The length of the box represents the interquartile range (IQR), within which $50 \%$ of the values are located. The lines through the center of the boxes represent the median. 
with F0/F1 METAVIR scores than among F3/F4 cases $(p<0.001)$ and were lower among F2 patients than among F3/F4 cases $(p<0.001)$.

The cut-off points for TE were established to assess the different degrees of liver fibrosis. Thus, employing a cut-off point of $>9.5 \mathrm{kPa}$ to predict the presence of advanced fibrosis and a cut-off point of $<7.5 \mathrm{kPa}$ for absence of fibrosis or mild fibrosis, we demonstrated an accuracy of 0.689 (95\% CI: $0.53-0.82$ ), a sensitivity of $69.5 \%$, a specificity of $66.7 \%$, a positive predictive value of $96.7 \%$, and a negative predictive value of $13.3 \%$. The Kappa coefficient of agreement was calculated to assess the degree of agreement between the results obtained for fibrosis stage by METAVIR score and by TE. A low agreement (Kappa 0.125) was demonstrated between the results obtained. We achieved a McNemar's test p-value of 0.0033 , rejecting the null hypothesis and showing a significant divergence between the results obtained for fibrosis stage by biopsy and by liver stiffness test.

Table 2 lists the TE results stratified by degree of fibrosis. The cut-off point used to separate stages F0/F1 from higher grades was $<7.5 \mathrm{kPa}$, which yielded a sen-

Table 2. Diagnostic Performance of Transient Elastography vs. Liver Biopsies for the Assessment of Fibrosis in Post-Liver Transplant Patients

\begin{tabular}{lcccc}
\hline Variables* $^{*}$ & $\begin{array}{c}\text { Sensitivity } \\
(\%)\end{array}$ & $\begin{array}{c}\text { Specificity } \\
(\%)\end{array}$ & $\begin{array}{c}\text { Positive } \\
\text { Predictive } \\
\text { Value (\%) }\end{array}$ & $\begin{array}{c}\text { Negative } \\
\text { Predictive } \\
\text { Value (\%) }\end{array}$ \\
\hline F0/F1 & 56.8 & 75.0 & 91.3 & 27.3 \\
F2 & 0 & 82.5 & 0 & 86.9 \\
F3/F4 & 66.7 & 69.0 & 13.3 & 96.7 \\
\hline
\end{tabular}

*Cut-off points adopted: for stages F0/F1, liver stiffness $<7.5 \mathrm{kPa}$, for stage F2, liver stiffness $>7.5$ and $<9.5 \mathrm{kPa}$, and for F3/F4 $>9.5 \mathrm{kPa}$.

sitivity of $56.8 \%$ and a specificity of $75.0 \%$. The cut-off values adopted for stage F2 were $>7.5$ and $<9.5 \mathrm{kPa}$ and the cut-off for F3/F4 stages was $>9.5 \mathrm{kPa}$. Based on the results of the study sample, we observed an accuracy of 0.511 (95\% CI: $0.36-0.66)$ for TE against liver biopsy. Analysis of the Kappa coefficient showed a low agreement $($ Kappa $=0.095)$ between the results obtained for liver stiffness by TE and liver biopsy findings, which are considered the gold standard tests. A McNemar's test p-value of 0.0019 was obtained, showing a significant divergence between the fibrosis stages results obtained with the two methods in the population assessed after LT.

\section{Discussion}

In recent decades LT has been used as a curative option for patients with end-stage liver disease. ${ }^{15}$ Survival of LT recipients has been extended by advances in surgical techniques and patient management after the surgical procedure, but strict follow-up must be maintained for early detection of any complications. ${ }^{8}$ Liver biopsy is traditionally considered the gold standard for assessing the degree of fibrosis and steatosis in patients with chronic liver disease, but it has limitations. ${ }^{10}$ Non-invasive methods, including TE, have been routinely implemented in the diagnosis and follow-up of these liver lesions, but in the context of post-LT patients, there are few reports available in the literature. In this study, carried out with the aim of evaluating the accuracy of liver fibrosis staging in a post-LT scenario in a referral center in southern Brazil, it was demonstrated that TE overestimates the stage of liver fibrosis when compared with the results obtained by liver biopsy.

In this study, liver disease caused by $\mathrm{HCV}$ was the main reason for LT, which was more frequent among males and was performed at a mean age of 58 years. Despite the steady increase in the prevalence of non-alcoholic steatohepatitis, the main indication for LT remains $\mathrm{HCV}$ in cirrhotic patients with or without hepatocellular carcinoma (HCC).${ }^{16}$ Recurrence of HCV after LT is frequent and deposition of fibrosis is accelerated in these cases and may be responsible for development of graft cirrhosis in up to $30 \%$ of patients five years after the procedure. ${ }^{1,3}$, ${ }^{17,18}$ The deposition of collagen fibers in liver tissue is the main determinant of long-term graft survival; for this reason, surveillance programs for fibrosis staging and early identification of HCC are extremely important to intervene in the therapeutic management of this population.

Performing a liver biopsy after LT is a tool employed as part of protocols in many clinical centers; however, it is subject to limitations such as the associated risk of morbidity, including the possibility of bleeding and perfusion, increased financial costs, and both intraobserver and interobserver disagreement in interpretation., 10, 18 These considerations are important, given the need for longitudinal follow-up of recurrent fibrosis. These limitations led to the development of noninvasive methods that have gained popularity in current clinical practice. One of them is TE, used for analysis of liver stiffness and steatosis. ${ }^{5,10,19}$

In this study, we observed that the result obtained for liver stiffness by TE overestimates the stage of liver fibrosis and demonstrated low agreement between techniques, intermediate sensitivity, and intermediate specificity. It is worse for advanced fibrosis stages (F3/F4) compared 
to mild and intermediate cases. It is worth mentioning that this result may be influenced by the retrospective and observational nature of the present study. Futhermore, another limitation of the study is the restricted sample size, especially for cases with advanced fibrosis, and this may influence the results obtained. Steadman et al. performed a systematic review with the aim of evaluating the efficacy of TE compared to liver biopsy for staging fibrosis in adults undergoing LT for different liver etiologies, demonstrating a sensitivity ranging from 0.67 to $0.92 \%$ and a specificity ranging from 0.72 to $0.95 \%$, results similar to those found by our group. ${ }^{20} \mathrm{~A}$ prospective study that compared indirect markers in contrast to liver biopsy for the detection and staging of fibrosis in allografts in patients undergoing living donor LT for HCV-related complications, concluded that there was no statistical correlation between the results obtained for stiffness and liver biopsy, and TE should not be recommended as an alternative technique in this situation. ${ }^{18}$ Also similar to our data, Barrault et al. observed a significant difference between stages F0/F1 and F2 versus F3/F4 in the diagnostic value of liver stiffness. Nevertheless, they concluded that the performance of TE is able to accurately identify LT recipients with significant fibrosis. ${ }^{21}$ Nascimbeni et al., in a retrospective study, examined the variability of shortterm TE measurements in patients with no or minimal progression/regression of chronic liver disease. Patients were appropriately selected for stable fibrotic disease and well-documented for confounding profibrotic factors and confounders of liver stiffness. The authors demonstrated a large intrinsic variability of repeated elastography measurements that was not related to changes in fibrosis but to operator-related and patient-related factors, reporting that elastography alone may not be sufficient for a reliable fibrosis follow-up in patients with chronic liver diseases. ${ }^{22}$

Several studies in the literature report that TE provides good accuracy for the identification of patients with significant fibrosis, and can be considered an alternative to liver biopsy, reducing the number of invasive procedures in the post-LT population; however, in this study, low accuracy was observed using TE for fibrosis staging. $6,9,17,23$ Moreover, the diagnostic performance of TE was less accurate in patients with obesity and/or large amounts of chest wall fat and in cirrhotic with ascites (although ascites itself is considered as a sign of cirrhosis/portal hypertension in most cases). ${ }^{5,23}$ In our study, most of the cases evaluated were overweight or grade I obese, which partly explains the low accuracy obtained for fibrosis staging when comparing the two techniques. Additionally, we observed a substantial increase in serum aminotransferase levels.

\section{Conclusion}

In summary, our data demonstrate that $\mathrm{TE}$ overestimates the stage of liver fibrosis compared to the gold standard, with low agreement, sensitivity, and specificity for the ability to distinguish individual fibrosis stages. We believe that there is a need to standardize specific $\mathrm{TE}$ values for each histological stage, in order to make it a more effective examination for assessment of the degree of fibrosis and to offer some benefit and comfort to post-LT patients. However, adequate clinical judgment is extremely important for the interpretation of the results obtained, and liver biopsy remains the main tool for the analysis of complex disease and when there are discrepancies between clinical symptoms and the extent of fibrosis assessed by non-invasive approaches.

Declaration of Interest. Authors have nothing to disclose.

Consent for Publication. Anonymized data were used for the elaboration of this article, which did not distort its scientific value.

Intellectual Property. The authors declare that the data, figures and tables that appear in this article are original and were made in their belonging institutions.

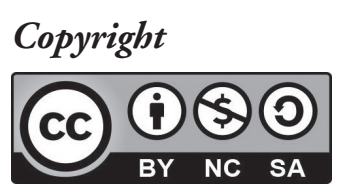

(C) 2021 Acta Gastroenterológica latinoamericana. This is an openaccess article released under the terms of the Creative Commons Attribution (CC BY-NC$S A$ 4.0) license, which allows non-commercial use, distribution, and reproduction, provided the original author and source are acknowledged.

Cite this article as: Pereira Matheus HM, dos Santos DC, Trucollo Michalczuk M, et al. Transient Hepatic Elastography in the Assessment of Liver Fibrosis in Patients After Liver Transplantation. Acta Gastroenterol Latinoam. 2021;51(3):314-20. https://doi.org/10.52787/wdom2933

\section{References}

1. Bhat M, Tazari M, Sebastiani G. Performance of transient elastography and serum fibrosis biomarkers for non-invasive evaluation of recurrent fibrosis after liver transplantation: A meta-analysis. PLoS One. 2017;12(9):e0185192.

2. Hagan M, Asrani SK, Talwalkar J. Non-invasive assessment of liver fibrosis and prognosis. Expert Rev Gastroenterol Hepatol. 2015;9(10):1251-60. 
3. Crespo G, Lens S, Gambato M, Carrión JA, Mariño Z, Londoño $\mathrm{MC}$, et al. Liver stiffness 1 year after transplantation predicts clinical outcomes in patients with recurrent hepatitis C. Am J Transplant. 2014;14(2):375-83.

4. Taylor RS, Taylor RJ, Bayliss S, Hagstrom H, Nasr P, Schattenberg JM, et al. Association Between Fibrosis Stage and Outcomes of Patients with Non-Alcoholic Fatty Liver Disease: a Systematic Review and Meta-Analysis. Gastroenterology. 2020.

5. Lambrecht J, Verhulst S, Mannaerts I, Reynaert H, van Grunsven LA. Prospects in non-invasive assessment of liver fibrosis: Liquid biopsy as the future gold standard? Biochim Biophys Acta Mol Basis Dis. 2018;1864(4 Pt A):1024-36.

6. Della-Guardia B, Evangelista AS, Felga GE, Marins LV, Salvalaggio PR, Almeida MD. Diagnostic Accuracy of Transient Elastography for Detecting Liver Fibrosis After Liver Trannsplantation: A Specific Cut-Off Value Is Really Needed? Dig Dis Sci. 2017;62(1):264-72.

7. Winters AC, Mittal R, Schiano TD. A review of the use of transient elastography in the assessment of fibrosis and steatosis in the post-liver transplant patient. Clin Transplant. 2019;33(10):e13700.

8. Liu WY, Wang JH, Guo Y, Wang X, Wu XD, Xu CS, et al. Transient elastography for assessment of fibrosis and steatosis of liver grafts from brain-death donors. Clin Res Hepatol Gastroenterol. 2020.

9. Lutz HH, Schroeter B, Kroy DC, Neumann U, Trautwein C, Tischendorf JJ. Doppler Ultrasound and Transient Elastography in Liver Transplant Patients for Noninvasive Evaluation of Liver Fibrosis in Comparison with Histology: A Prospective Observational Study. Dig Dis Sci. 2015;60(9):2825-31.

10. Liver EAfSo, Higado ALpeEd. EASL-ALEH Clinical Practice Guidelines: Non-invasive tests for evaluation of liver disease severity and prognosis. J Hepatol. 2015;63(1):237-64.

11. Pfeiffenberger J, Hornuss D, Houben P, Wehling C, Von Haken R, Loszanowski V, et al. Routine Liver Elastography Could Predict Actuarial Survival after Liver Transplantation. J Gastrointestin Liver Dis. 2019;28(3):271-7.

12. Laish I, Braun M, Mor E, Sulkes J, Harif Y, Ben Ari Z. Metabolic syndrome in liver transplant recipients: prevalence, risk factors, and association with cardiovascular events. Liver Transpl. 2011;17(1):15-22.

13. Desai S, Hong JC, Saab S. Cardiovascular risk factors following orthotopic liver transplantation: predisposing factors, incidence and management. Liver Int. 2010;30(7):948-57.
14. ABESO. Diretrizes brasileiras de obesidade 2016/ABESO. 4.ed. - São Paulo SdS-.

15. Lv T, Kong L, Yang J, Wu H, Wen T, Jiang L. The postoperative hepatic artery resistance index after living donor liver transplantation can predict early allograft dysfunction. Medicine (Baltimore). 2020;99(4):e18677.

16. Wong RJ, Aguilar M, Cheung R, Perumpail RB, Harrison SA, Younossi ZM, et al. Nonalcoholic steatohepatitis is the second leading etiology of liver disease among adults awaiting liver transplantation in the United States. Gastroenterology. 2015;148(3):547-55.

17. Corradi F, Piscaglia F, Flori S, D'Errico-Grigioni A, Vasuri F, Tamé MR, et al. Assessment of liver fibrosis in transplant recipients with recurrent HCV infection: usefulness of transient elastography. Dig Liver Dis. 2009;41(3):217-25.

18. El-Meteini M, Sakr M, Eldorry A, Mohran Z, Abdelkader NA, Dabbous H, et al. Non-Invasive Assessment of Graft Fibrosis After Living Donor Liver Transplantation: Is There Still a Role for Liver Biopsy? Transplant Proc. 2019;51(7):2451-6.

19. Nacif LS, Paranagua-Vezozzo DC, Matsuda A, Alves VAF, Carrilho FJ, Farias AQ, et al. Higher Values In Liver Elastography and Meld Score Are Mortality Predictors On Liver Transplant Waiting List. Arq Bras Cir Dig. 2018;31(1):e1360.

20. Steadman R, Myers RP, Leggett L, Lorenzetti D, Noseworthy T, Rose $\mathrm{S}$, et al. A health technology assessment of transient elastography in adult liver disease. Can J Gastroenterol. 2013;27(3):14958.

21. Barrault C, Roudot-Thoraval F, Tran Van Nhieu J, Atanasiu C, Kluger MD, Medkour F, et al. Non-invasive assessment of liver graft fibrosis by transient elastography after liver transplantation. Clin Res Hepatol Gastroenterol. 2013;37(4):347-52.

22. Nascimbeni F, Lebray P, Fedchuk L, Oliveira CP, Alvares-da-Silva MR, Varault A, et al. Significant variations in elastometry measurements made within short-term in patients with chronic liver diseases. Clin Gastroenterol Hepatol. 2015;13(4):763-71.e1-6.

23. Carrión JA, Navasa M, Bosch J, Bruguera M, Gilabert R, Forns $\mathrm{X}$. Transient elastography for diagnosis of advanced fibrosis and portal hypertension in patients with hepatitis $\mathrm{C}$ recurrence after liver transplantation. Liver Transpl. 2006;12(12):1791-8. 